Article

\title{
Wave Force Characteristics of Large-Sized Offshore Wind Support Structures to Sea Levels and Wave Conditions
}

\author{
Youn-Ju Jeong *, Min-Su Park, Jeongsoo Kim® and Sung-Hoon Song \\ Infrastructure Safety Research Institute, Korea Institute of Civil Engineering and Building Technology, \\ Goyang-Si, Gyeonggi-Do 10223, Korea; mspark@kict.re.kr (M.-S.P.); jeongsookim@kict.re.kr (J.K.); \\ songsunghoon@kict.re.kr (S.-H.S.) \\ * Correspondence: yjjeong@kict.re.kr; Tel.: +82-31-910-0136; Fax: +82-31-910-0121
}

Received: 18 January 2019; Accepted: 29 April 2019; Published: 6 May 2019

\begin{abstract}
This paper presents the results of wave force tests conducted on three types of offshore support structures considering eight waves and three sea levels to investigate the corresponding wave forces. As a result of this study, it is found that the occurrence of shoaling in shallow water induces a significant increase of the wave force. Most of the test models at the shallow water undergo a nonlinear increase of the wave force with higher wave height increasing. In addition, the larger the diameter of the support structure within the range of this study, the larger the diffraction effect is, and the increase in wave force due to shoaling is suppressed. Under an irregular wave at the shallow water, the wave force to the long-period wave tends to be slightly higher than that of the short period wave since the higher wave height component included in the irregular wave has an influence on the shoaling. In addition, it is found that the influence of shoaling under irregular wave becomes more apparent in the long period.
\end{abstract}

Keywords: wave force; large-sized support structure; sea levels; wave conditions; test; shoaling

\section{Introduction}

In response to the growing demand for renewable energy, offshore wind turbines have recently seen their capacity increased from 1-3 MW to 7-12 MW. The increase of the turbine capacity means enlarged turbines and enlarged support structures undergoing extreme environmental conditions including wind, waves, and tides. This enlargement of the offshore support structure improves the strength and the stiffness but makes it subject to complicated wave forces with a wider exposed area and complex details. It is thus important to evaluate exactly the wave force and wave-induced overturning moment applied to the support structure to secure its structural safety [1,2].

In the hydrodynamic and structural analyses conducted during the structural design, the wave forces acting on the support structure are calculated based upon the Morison equation or diffraction theory. As shown in Figures 1 and 2, the wave nonlinearity and wave diffraction of the wave force applied to the offshore support structure depends on its shape and size as well as on the sea levels and wave conditions including the wave height, period, and length [3-8]. Shoaling is a phenomenon that occurs when a wave passes through a shallow water depth, in which the wave crest increases sharply and the wave trough flattens, as presented in Figure 1, and it is believed that nonlinear variation of wave height due to shoaling affects wave force [4]. Diffraction is a phenomenon in which fluid flow is diffused around a circle when the fluid passes through a large circle [7], as presented in Figure 2, which is known to generate diffracted wave force on the circular backside and to have lower wave pressure on the circular surface. 
Recalling that the monopile [9], GBS (gravity based structure) [10,11], and hybrid support structures $[12,13]$ are currently preferred to support offshore wind turbines and that irregular waves are commonly applied to obtain a more accurate wave force [14,15], the wave force acting on the offshore structure needs to be evaluated experimentally for specific shapes and specific design wave conditions in case of large structures because of the resulting higher nonlinearity and complexity of the wave force $[3,6-8,16]$. Chella et al. [7] summarized the influences of the breaking waves on offshore wind turbine structures, in which considerable uncertainties in the estimation of hydrodynamic loads are caused by the breaking waves in shallow water. Christensen et al. [3] analytically investigated wave run-up and wave forces on a vertical circular cylinder and found that the run-up is higher when the wave is just about to break compared to the fully broken wave. De Vos et al. [6] studied the influence of wave condition and water depth on run-up and wave force including both regular and irregular waves. The results showed that the shape of the support structure substantially affects the maximum run-up level, increasing the expected run-up value. Marino et al. [17] studied a fully nonlinear wave model to simulating breaking wave impact loads on offshore wind turbines. Schloer et al. [15] studied the wave forces on a monopile from a nonlinear irregular unidirectional wave model and reported that nonlinear irregular waves give rise to larger extreme wave forces than those predicted by linear theory. Aashamar [18] and Ros [19] studied the slamming forces from plunging breaking waves on truss support structures in shallow water. Kudeih et al. [20] have studied of wave force on the array of a vertical cylinder in shallow water. Herbert et al. [5] investigated the shoaling evolution of the wave frequency-directional spectrum with field and laboratory observations and a numerical model. Tsai et al. [14] estimated the transformation of wave shoaling and breaking which are essential for nearshore hydrodynamics and the design of the coastal structure and evaluated some criteria for wave shoaling. Henry et al. [21] provided a practical method for estimating the drag force in shoaling conditions, where the effects of shoaling and breaking waves were included by adopting wave height distribution.

In this study, wave force tests were conducted on three types of offshore support structures and three sea levels to investigate the effect of wave nonlinearity on wave forces, such as shoaling dependent on the sea condition and diffraction effect depending on the diameter of the support structure. The considered structures were the monopile, GBS, and hybrid support structures and the considered sea levels were HSWL (high still water level), MSL (mean sea level), and LSWL (low still water level). Moreover, five regular and three irregular wave conditions were applied to totalize 84 different test cases.

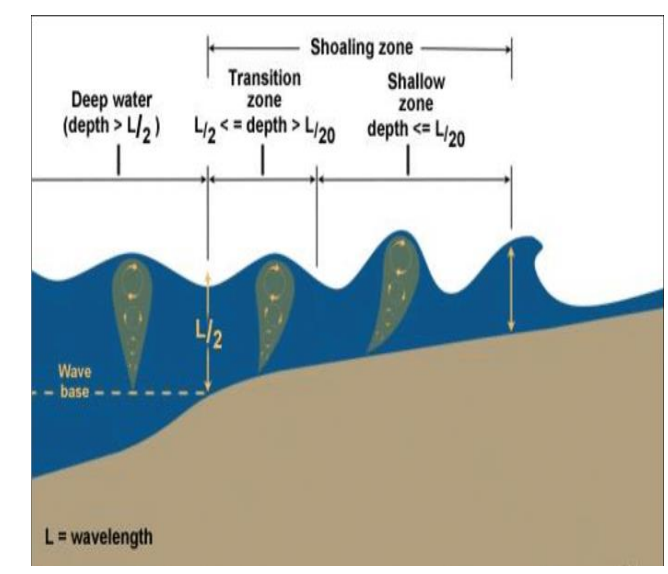

Figure 1. Wave nonlinearity: shoaling. 


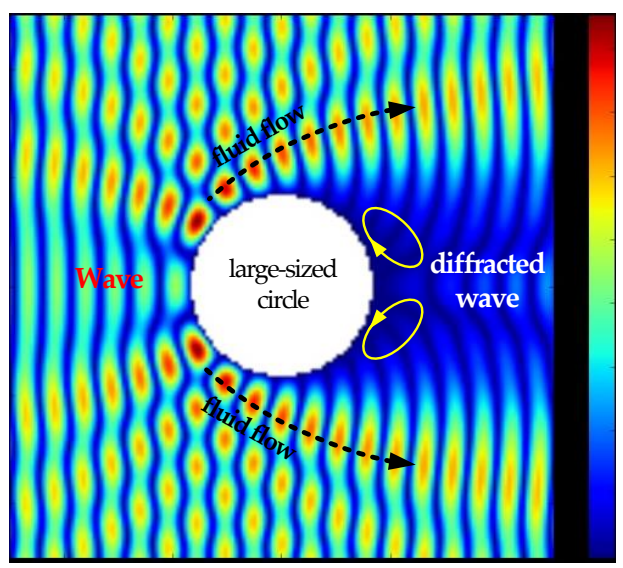

Figure 2. Wave diffraction in large-sized member.

\section{Wave Force Tests}

\subsection{Test Models}

Figure 3 shows the test models of the monopile, GBS, hybrid offshore support structures considered in this study. The models were designed and fabricated with Froude scale law of 1:25, and present the same total weight and height. For the hybrid model, since the upper part exhibits multiple legs, the wave force will vary according to the wave direction. Therefore, the maximum wave force is also examined for the incident wave of $45^{\circ}$ by repositioning the model to realize an angle of $45^{\circ}$ with the direction of the wave. Table 1 lists the details of the three support models, where the dimensions indicate the dimension of the test model scaled down to 1:25.

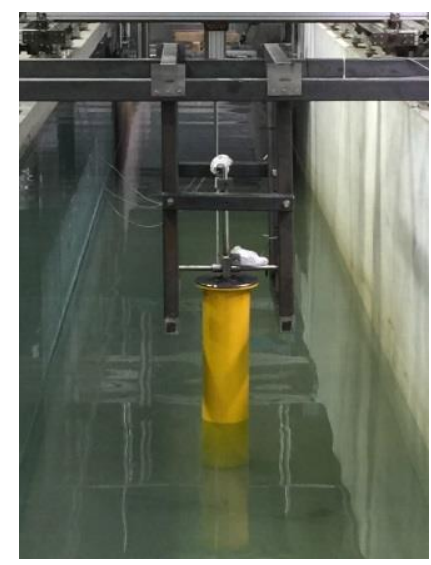

(a)

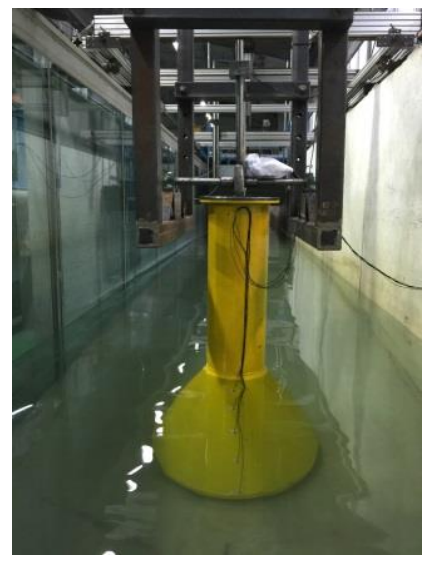

(b)

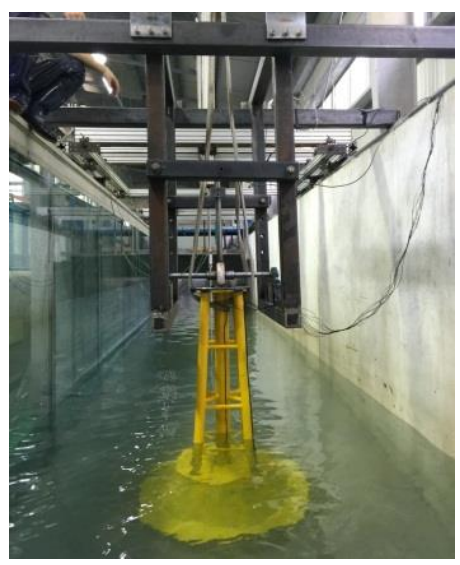

(c)

Figure 3. Test models: (a) monopile; (b) GBS (gravity based structure); (c) hybrid.

Table 1. Details of test models.

\begin{tabular}{cccccc}
\hline \multirow{2}{*}{ Type } & \multirow{2}{*}{ Dimensions $(\mathbf{m m})$} & Weight $\mathbf{( k g})$ & \multicolumn{2}{c}{ Wave Projected Area $\left.\mathbf{( c m}^{\mathbf{2}}\right)$} \\
\cline { 4 - 6 } & & & HSWL & MSL & LSWL \\
\hline Monopile & $240\left(\mathrm{D}_{1}\right) \times 240\left(\mathrm{D}_{2}\right) \times 1500(\mathrm{H})$ & 203.00 & 2328.0 & 1920.0 & 1512.0 \\
GBS & $260\left(\mathrm{D}_{1}\right) \times 740\left(\mathrm{D}_{2}\right) \times 1500(\mathrm{H})$ & 203.00 & 4442.0 & 4000.0 & 3471.3 \\
Hybrid & $272\left(\mathrm{D}_{1}\right) \times 740\left(\mathrm{D}_{2}\right) \times 1500(\mathrm{H})$ & 203.00 & 3924.8 & 3462.4 & 3000.0 \\
$\left(0^{\circ}, 45^{\circ}\right)$ & $\mathrm{D}_{1}=(4 \cdot \varnothing 48+\varnothing 80)$ & & & & \\
\hline
\end{tabular}

$\mathrm{D}_{1}$ : top diameter, $\mathrm{D}_{2}$ : bottom diameter, $\mathrm{H}$ : height, Ø: pile diameter. 


\subsection{Test Setup}

The wave force tests were conducted in July of 2016 at the flume of Cheonnam National University, South Korea. The flume shown in Figure 4 has dimensions of $100 \mathrm{~m}(\mathrm{~L}) \times 2.0 \mathrm{~m}(\mathrm{~W}) \times 3.0 \mathrm{~m}(\mathrm{H})$. The jig shown in Figures 5 and $6 a$ was designed and fabricated to allow wave-induced swing motion of the test models with minimal friction. A steel bar was attached to the jig to restrain the swing motion and the restraining force applied to the test model was measured by means of a load-cell installed on the bar (Figure 6a). The so-measured constraint force is equal to the wave force acting on the test model because the test model maintains equilibrium to the swing motion as figured in Figure 5 . This test method offers the advantage to prevent malfunction and error of the sensor in seawater since the load-cell is located outside in the air [16]. In addition, five to eight hydraulic pressure gauges are attached to the front side of the test models as shown in Figure $6 \mathrm{~b}$ to measure the wave pressure distribution acting in the normal direction on the wave along the water depth.
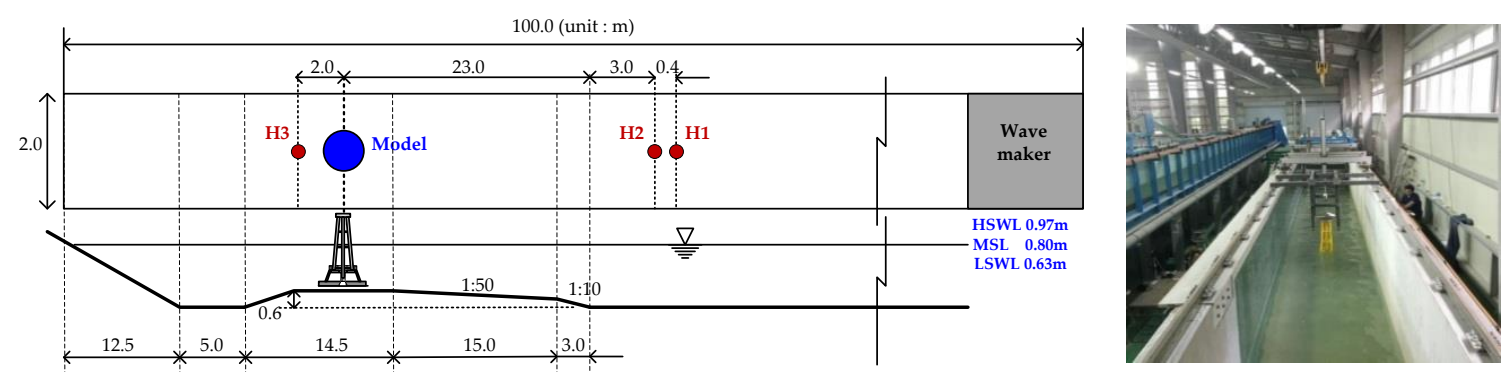

Figure 4. Plan and view of the flume for wave force tests.
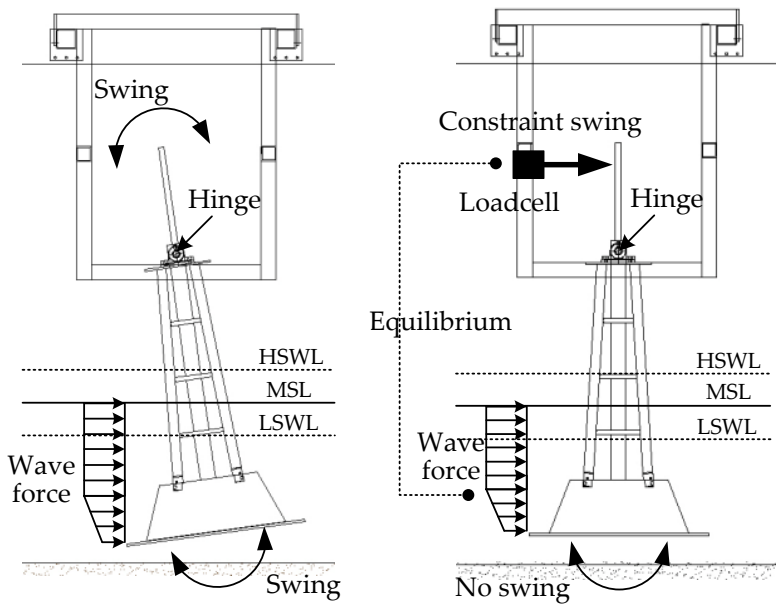

Figure 5. Concept of wave force measurement.

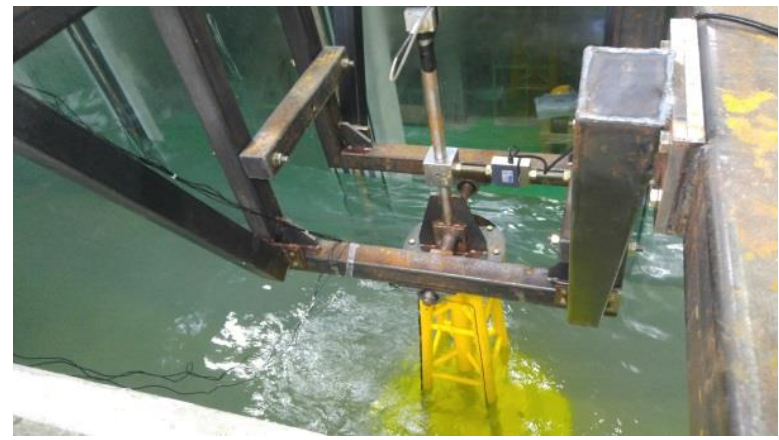

(a)

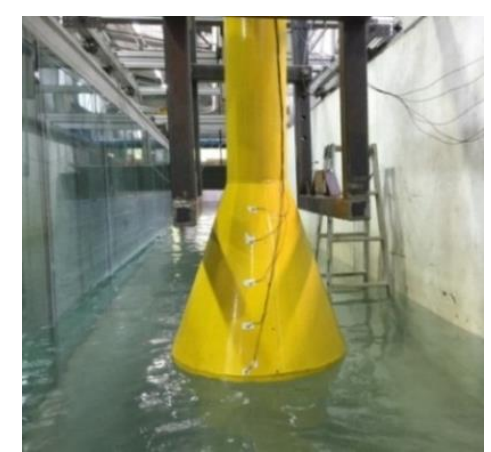

(b)

Figure 6. Installation of load-cell and wave pressure gauge: (a) load-cell; (b) wave pressure gauge. 


\subsection{Wave Conditions and Sea Levels}

The support structure models were tested under the wave conditions listed in Table 2 including five regular waves and three irregular waves. The wave variables adopted for the wave force test are the wave periods $\left(\mathrm{T}_{\mathrm{w}}\right)$ and wave heights $\left(\mathrm{H}_{\mathrm{w}}\right)$. Accordingly, three wave periods $\left(\mathrm{T}_{\mathrm{w}}\right)$ of $7.5 \mathrm{~s}, 9.5 \mathrm{~s}$. and $13.7 \mathrm{~s}$ and three wave heights $\left(\mathrm{H}_{\mathrm{w}}\right)$ of $3.435 \mathrm{~m}, 6.87 \mathrm{~m}$, and $12.78 \mathrm{~m}$ were selected for the full-scale models, where $\mathrm{H}_{\mathrm{w}}$ was determined from significant wave height for the southwest sea of South Korea. These values were then scaled down to respectively, $1.5 \mathrm{~s}, 1.9 \mathrm{~s}$, and $2.74 \mathrm{~s}$, and $0.137 \mathrm{~m}, 0.275 \mathrm{~m}$, and $0.511 \mathrm{~m}$ for the test models using a Froude scale law of $1 / \lambda$ for the wave height $\left(H_{w}\right)$ and $1 / \sqrt{ } \lambda$ for the wave period $\left(\mathrm{T}_{\mathrm{w}}\right)$. The three irregular waves were generated with the Pierson-Moskowitz spectrum according to the three peak wave periods $\left(\mathrm{T}_{\mathrm{w}}\right)$ of $1.5 \mathrm{~s}, 1.9 \mathrm{~s}$. and $2.74 \mathrm{~s}$ for the test model, where an irregular wave was generated by setting a random number 200 times on the wave maker. Reliability of generated irregular wave was secured by comparing the energy of the Pierson-Moskowitz spectrum with the energy of the measured wave data for $5 \mathrm{~min}$. Note that a wave height of $9.50 \mathrm{~m}$ was applied instead of $12.78 \mathrm{~m}$ for LSWL to prevent wave breaking at shallow water depth [22].

Along with these wave variables, three sea levels were also applied in the wave force tests of Table 1. These sea levels (h) were selected with respect to the design guideline for the southwest sea of South Korea and were 24.25 m, 20.0 m, and $15.75 \mathrm{~m}$ for HSWL, MSL, and LSWL, respectively. These values were also scaled down to $0.97 \mathrm{~m}, 0.80 \mathrm{~m}$, and $0.63 \mathrm{~m}$ by the scale factor of $1 / \lambda$.

\section{Test Results}

\subsection{Wave Force Measurement}

The wave force tests for the small-scale models were carried out for $300 \mathrm{~s}$. Among the measured data during $300 \mathrm{~s}$, the 60 -s data measured from $200 \mathrm{~s}$ to $260 \mathrm{~s}$ by the load-cell were used as representative values for the analysis of the wave force acting on the test models for the regular waves, and the full data of $300 \mathrm{~s}$ were used for the irregular waves. The noise of the measured data set was eliminated using the moving average data processing method.

Figures 7-9 plot the results of the wave force tests measured for each of the considered test models under regular wave conditions. The minimum and maximum magnitudes of the wave forces were calculated for the small-scale models and converted for the real-scale models using the Froude scale law.

Table 2. Wave conditions.

\begin{tabular}{|c|c|c|c|c|c|c|c|c|c|}
\hline \multirow{2}{*}{ Wave } & \multirow{2}{*}{ No. } & \multicolumn{2}{|c|}{ HSWL } & \multicolumn{2}{|c|}{ MSL } & \multicolumn{2}{|c|}{ LSWL } & \multicolumn{2}{|c|}{ Variables } \\
\hline & & $\mathrm{H}_{\mathrm{W}}(\mathrm{m})$ & $T_{W}(s)$ & $\mathrm{H}_{\mathrm{W}}(\mathrm{m})$ & $\mathrm{T}_{\mathrm{W}}(\mathrm{s})$ & $\mathrm{H}_{\mathrm{W}}(\mathrm{m})$ & $\mathrm{T}_{\mathrm{W}}(\mathrm{s})$ & $\mathbf{T}_{\mathbf{W}}$ & $\mathbf{H}_{W}$ \\
\hline \multirow{5}{*}{ Regular } & R-\#1 & $\begin{array}{c}0.137 \\
(3.435)\end{array}$ & $\begin{array}{l}1.500 \\
(7.5)\end{array}$ & $\begin{array}{c}0.137 \\
(3.435)\end{array}$ & $\begin{array}{l}1.500 \\
(7.5)\end{array}$ & $\begin{array}{c}0.137 \\
(3.435)\end{array}$ & $\begin{array}{l}1.500 \\
(7.5)\end{array}$ & $\bullet$ & \\
\hline & R-\#2 & $\begin{array}{c}0.137 \\
(3.435)\end{array}$ & $\begin{array}{l}1.900 \\
(9.5)\end{array}$ & $\begin{array}{c}0.137 \\
(3.435)\end{array}$ & $\begin{array}{c}1.900 \\
(9.5)\end{array}$ & $\begin{array}{c}0.137 \\
(3.435)\end{array}$ & $\begin{array}{c}1.900 \\
(9.5)\end{array}$ & $\bullet$ & \\
\hline & R-\#3 & $\begin{array}{c}0.137 \\
(3.435)\end{array}$ & $\begin{array}{l}2.740 \\
(13.7)\end{array}$ & $\begin{array}{c}0.137 \\
(3.435)\end{array}$ & $\begin{array}{l}2.740 \\
(13.7)\end{array}$ & $\begin{array}{c}0.137 \\
(3.435)\end{array}$ & $\begin{array}{l}2.740 \\
(13.7)\end{array}$ & $\bullet$ & $\bullet$ \\
\hline & R-\#4 & $\begin{array}{c}0.275 \\
(6.870)\end{array}$ & $\begin{array}{l}2.740 \\
(13.7)\end{array}$ & - & - & $\begin{array}{c}0.275 \\
(6.870)\end{array}$ & $\begin{array}{l}2.740 \\
(13.7)\end{array}$ & & $\bullet$ \\
\hline & R-\#5 & $\begin{array}{c}0.511 \\
(12.78)\end{array}$ & $\begin{array}{l}2.740 \\
(13.7)\end{array}$ & $\begin{array}{c}0.511 \\
(12.78)\end{array}$ & $\begin{array}{l}2.740 \\
(13.7)\end{array}$ & $\begin{array}{c}0.380 \\
(9.500)\end{array}$ & $\begin{array}{l}2.740 \\
(13.7)\end{array}$ & & $\bullet$ \\
\hline \multirow{3}{*}{ Irregular } & IR-\#1 & $\begin{array}{c}0.137 \\
(3.435)\end{array}$ & $\begin{array}{l}1.500 \\
(7.5)\end{array}$ & $\begin{array}{c}0.137 \\
(3.435)\end{array}$ & $\begin{array}{l}1.500 \\
(7.5)\end{array}$ & $\begin{array}{c}0.137 \\
(3.435)\end{array}$ & $\begin{array}{l}1.500 \\
(7.5)\end{array}$ & $\bullet$ & \\
\hline & IR-\#2 & $\begin{array}{c}0.137 \\
(3.435)\end{array}$ & $\begin{array}{l}1.900 \\
(9.5)\end{array}$ & $\begin{array}{c}0.137 \\
(3.435)\end{array}$ & $\begin{array}{l}1.900 \\
(9.5)\end{array}$ & $\begin{array}{c}0.137 \\
(3.435)\end{array}$ & $\begin{array}{c}1.900 \\
(9.5)\end{array}$ & $\bullet$ & \\
\hline & IR-\#3 & $\begin{array}{c}0.137 \\
(3.435)\end{array}$ & $\begin{array}{l}2.747 \\
(13.7)\end{array}$ & $\begin{array}{c}0.137 \\
(3.435)\end{array}$ & $\begin{array}{l}2.300 \\
(11.5)\end{array}$ & $\begin{array}{c}0.137 \\
(3.435)\end{array}$ & $\begin{array}{l}2.747 \\
(13.7)\end{array}$ & $\bullet$ & \\
\hline
\end{tabular}

( ) outside: small-scale model, ( ) inside: full-scale model. 


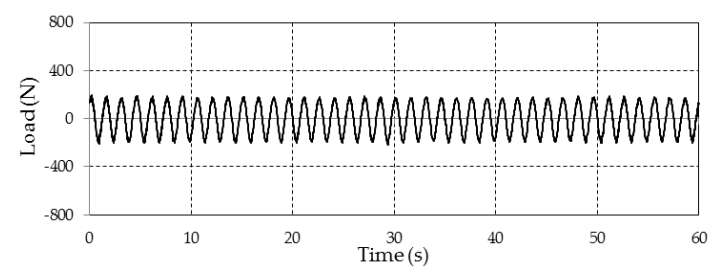

(a)

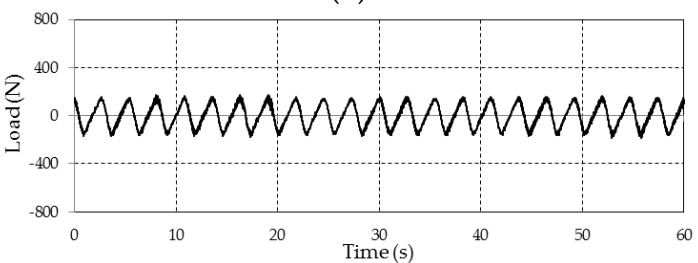

(c)

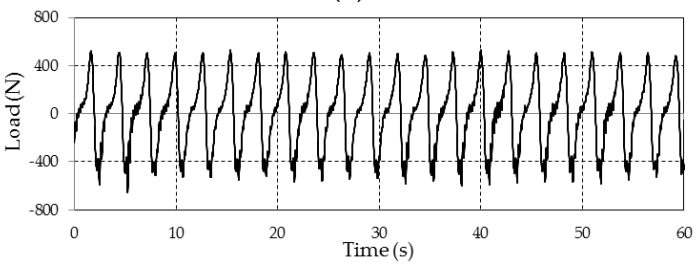

(e)

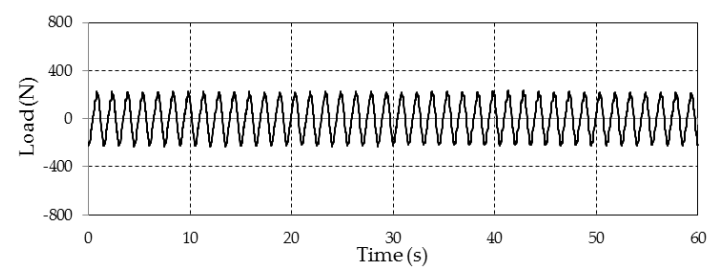

(b)

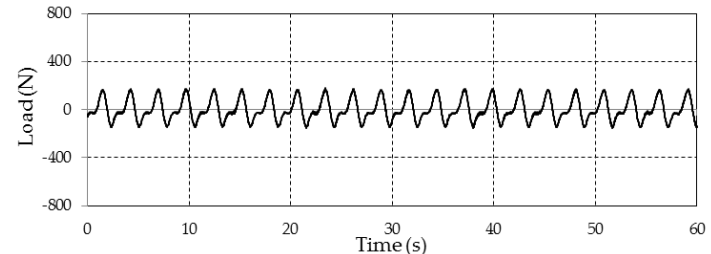

(d)

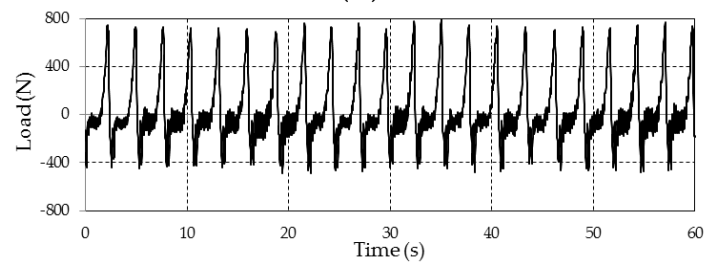

(f)

Figure 7. Measured wave forces for monopile under regular waves: (a) R-\#1: HSWL (high still water level); (b) R-\#1: LSWL (low still water level); (c) R-\#3: HSWL; (d) R-\#3: LSWL; (e) R-\#5: HSWL; (f) R-\#5: LSWL.

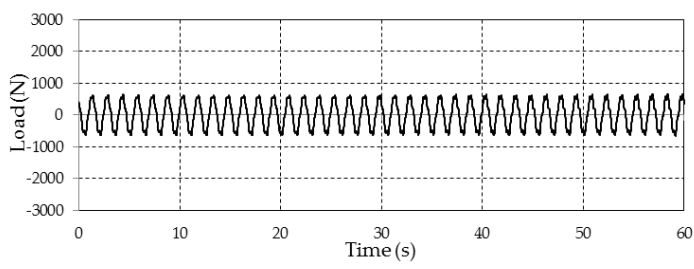

(a)

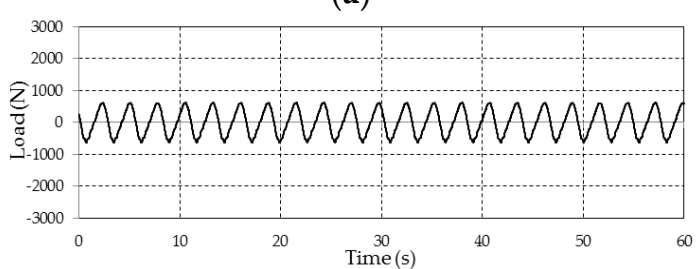

(c)

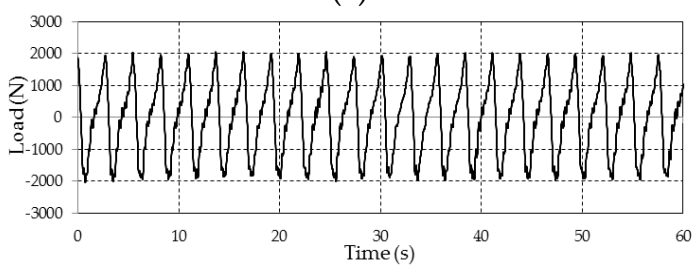

(e)

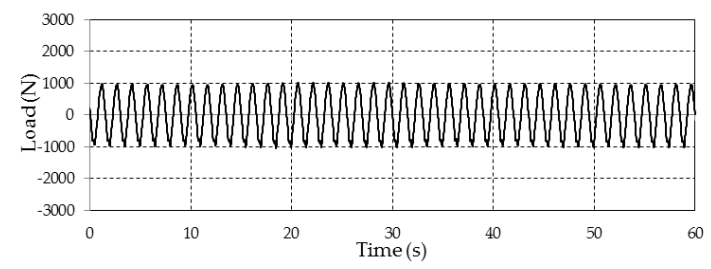

(b)

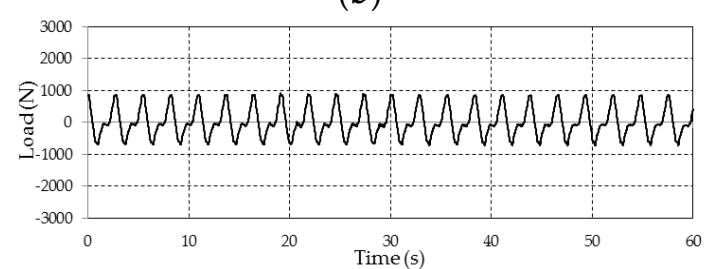

(d)

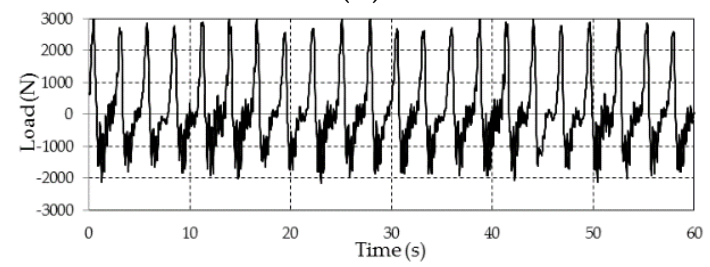

(f)

Figure 8. Measured wave forces for GBS under regular waves: (a) R-\#1: HSWL; (b) R-\#1: LSWL; (c) R-\#3: HSWL; (d) R-\#3: LSWL; (e) R-\#5: HSWL; (f) R-\#5: LSWL. 


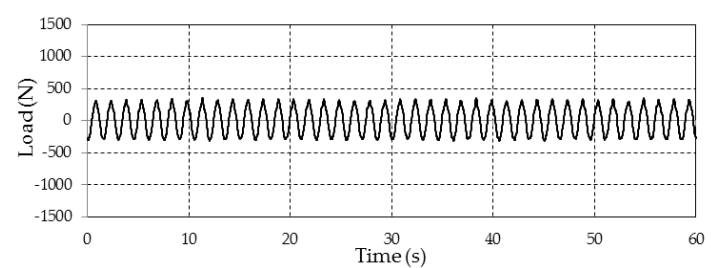

(a)

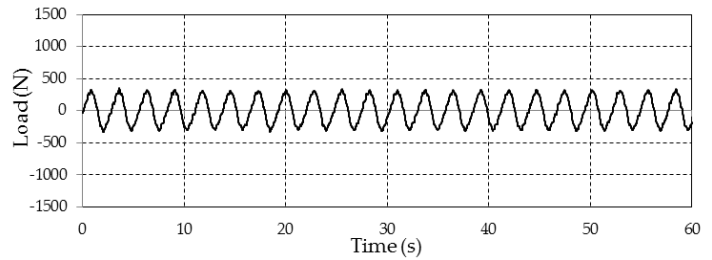

(c)

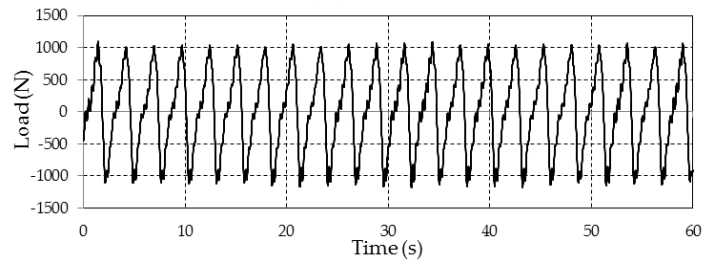

(e)

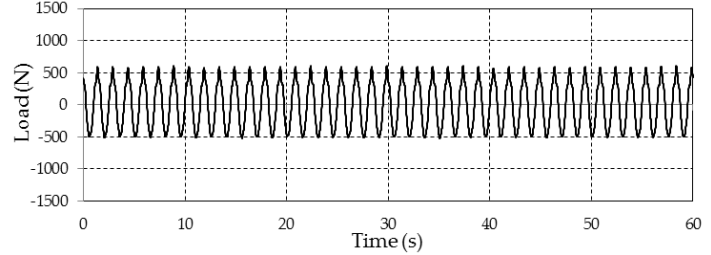

(b)

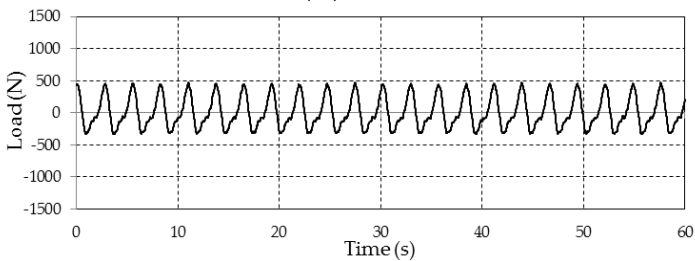

(d)

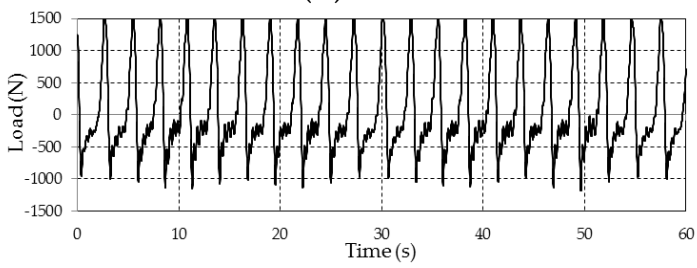

(f)

Figure 9. Measured wave forces for hybrid under regular waves (a) R-\#1: HSWL; (b) R-\#1: LSWL; (c) R-\#3: HSWL; (d) R-\#3: LSWL; (e) R-\#5: HSWL; (f) R-\#5: LSWL.

\subsection{Wave Forces According to Wave Periods of Regular Waves}

Table 3 summarizes the maximum amplitudes of the wave forces to wave periods for the real-scale models and Figure 10 plots the maximum amplitude of wave forces obtained under regular waves for the real-scale models of the three types of support structure. The measured wave forces exhibit a similar tendency according to the wave periods regardless of the sea level. According to the change of the wave period, the wave forces decrease gradually with longer wave periods from wave R-\#1 (7.5 s) to wave R-\#3 (15.5 s) in most of the support structures at the three sea levels [16,23,24]. The wave forces show a smaller decrease ratio according to the wave period at HSLW than at MSL and LSWL, with ranges of $0.80-0.97$ at HSWL, $0.57-0.70$ at MSL, and 0.69-0.78 at the LSWL.

Table 3. Summary of maximum wave forces for real-scale models: $\mathrm{P}_{\mathrm{w}}$ under regular waves.

\begin{tabular}{ccccccc}
\hline \multirow{2}{*}{ Sea Levels } & Wave & $\mathbf{P}_{\mathbf{w}}$ & Monopile & GBS & Hybrid 0 $^{\circ}$ & Hybrid 45 $^{\circ}$ \\
\cline { 2 - 7 } & & $\mathbf{s e c}$ & $\mathbf{k N}$ (Ratio) & kN (Ratio) & kN (Ratio) & kN (Ratio) \\
\hline \multirow{3}{*}{ HSWL } & R-\#1 & 7.5 & $973(1.00)$ & $2608(1.00)$ & $1140(1.00)$ & $1095(1.00)$ \\
& R-\#2 & 9.5 & $1024(1.05)$ & $2778(1.07)$ & $1141(1.00)$ & $1171(1.07)$ \\
& R-\#3 & 13.7 & $783(0.80)$ & $2377(0.91)$ & $1110(0.97)$ & $1047(0.96)$ \\
\hline \multirow{3}{*}{ MSL } & R-\#1 & 7.5 & $1095(1.00)$ & $4151(1.00)$ & $1730(1.00)$ & $1695(1.00)$ \\
& R-\#2 & 9.5 & $823(0.75)$ & $3793(0.91)$ & $1611(0.93)$ & $1569(0.93)$ \\
& R-\#3 & 13.7 & $627(0.57)$ & $2748(0.66)$ & $1198(0.69)$ & $1191(0.70)$ \\
\hline \multirow{3}{*}{ LSWL } & R-\#1 & 7.5 & $896(1.00)$ & $3738(1.00)$ & $1820(1.00)$ & $1743(1.00)$ \\
& R-\#2 & 9.5 & $717(0.80)$ & $2905(0.78)$ & $1562(0.86)$ & $1549(0.89)$ \\
& R-\#3 & 13.7 & $619(0.69)$ & $2906(0.78)$ & $1287(0.71)$ & $1282(0.74)$ \\
\hline
\end{tabular}

(ratio) $=($ wave force of $\mathrm{R}-\# \mathrm{~N}) /($ wave force of $\mathrm{R}-\# 1), \mathrm{N}=1,2,3$. 


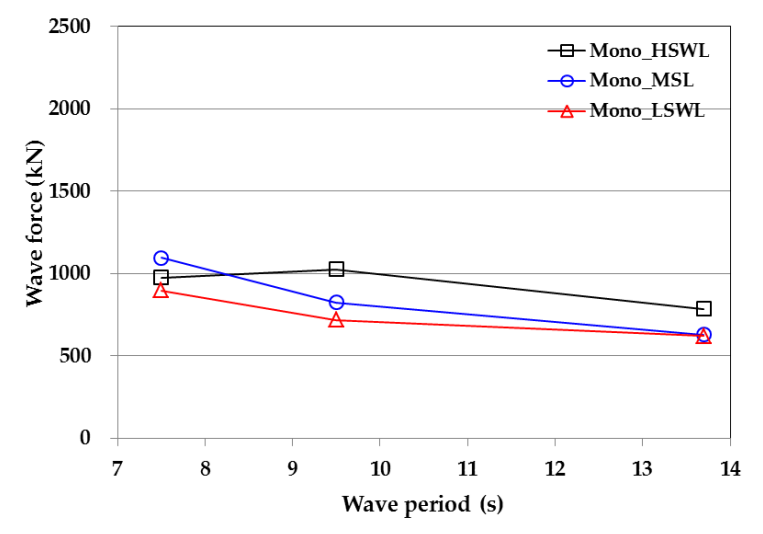

(a)

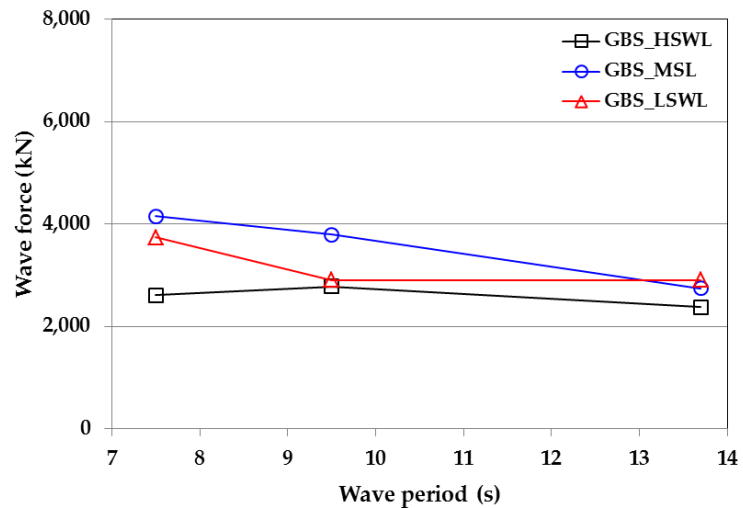

(b)

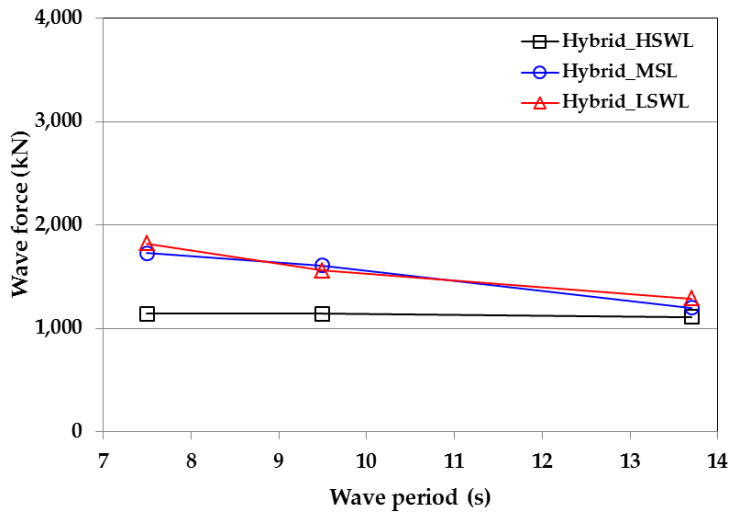

(c)

Figure 10. Wave force patterns to $P_{w}$ under regular waves: (a) monopile; (b) GBS; (c) hybrid.

By type of support structure, the variation of the wave force according to the wave period is larger in the monopile and smaller in the GBS and hybrid. With regard to the sea levels, the wave force variation of the monopile is about 0.80 at the HSWL, 0.57 at MSL, and 0.69 at LSWL, and that of the GBS is about 0.91 at HSWL, 0.66 at MSL, and 0.78 at LSWL. In addition, although there is no consistent tendency in the wave force according to the three sea levels for each of the three support structure types, the wave forces in MSL and LSWL are somewhat higher than those in HSWL for the GBS and hybrid. It is considered that the bottom structural members of these two types are composed of a large area and that as the water depth is lowered, these large area members act significantly as a projected area against the wave, as presented in Table 1, resulting in an increased total wave force. However, since the wave height $(3.435 \mathrm{~m})$ of this wave condition is not so large, the influence on the wave force is not so large. Judging by the overall trend, it is considered that the nonlinear wave force due to shoaling or diffraction does not occur or its effect is negligible at this wave condition because the wave height $(3.435 \mathrm{~m})$ of this wave condition is low.

\subsection{Wave Forces According to Wave Heights of Regular Waves}

Table 4 summarizes the maximum amplitudes of the wave forces to significant wave heights for the real-scale models and Figure 11 plots the maximum amplitude of wave forces obtained under a regular wave for the real-scale models of the three types of support structure. The wave force according to the wave height exhibits a different tendency for the three sea levels. According to the change of wave height at HSWL and MSL, all the models undergo an almost linear increase in the wave force with a higher wave height increasing from wave R-\#3 (3.435 m) to wave R-\#5 (12.78 m) [23-25], which is consistent with the linear wave theory with wave height. At HSWL, the wave force increases by about 1.85-2.08 times when the wave height doubles (2.00 times) from wave R-\#3 (3.435 m) to wave 
$\mathrm{R}$-\#4 (6.87 m). When the wave height increases by 3.72 times from wave R-\#3 (3.435 $\mathrm{m})$ to wave R-\#5 $(12.78 \mathrm{~m})$, the wave forces increase by about 3.27-3.47 times at HSWL and 3.11-3.79 times at MSL.

Table 4. Summary of maximum wave forces for real-scale models: $H_{w}$ under regular waves.

\begin{tabular}{ccccccc}
\hline \multirow{2}{*}{ Sea Levels } & Wave & $\mathbf{H}_{\mathbf{w}}$ & Monopile & GBS & Hybrid 0 $^{\circ}$ & Hybrid 45 $^{\circ}$ \\
\cline { 2 - 6 } & & $\mathbf{m}$ (Ratio) & $\mathbf{k N}$ (Ratio) & $\mathbf{k N}$ (Ratio) & $\mathbf{k N ~ ( R a t i o )}$ & $\mathbf{k N ~ ( R a t i o )}$ \\
\hline \multirow{3}{*}{ HSWL } & R-\#3 & $3435(1.00)$ & $783(1.00)$ & $2377(1.00)$ & $1110(1.00)$ & $1047(1.00)$ \\
& R-\#4 & $6870(2.00)$ & $1451(1.85)$ & $4877(2.05)$ & $2238(2.02)$ & $2180(2.08)$ \\
& R-\#5 & $12,780(3.72)$ & $2610(3.33)$ & $7774(3.27)$ & $3752(3.38)$ & $3633(3.47)$ \\
\hline \multirow{2}{*}{ MSL } & R-\#3 & $3435(1.00)$ & $627(1.00)$ & $2748(1.00)$ & $1198(1.00)$ & $1191(1.00)$ \\
& R-\#4 & $6870(2.00)$ & - & - & - & - \\
& R-\#5 & $12,780(3.72)$ & $2375(3.79)$ & $8541(3.11)$ & $4070(3.40)$ & $4087(3.43)$ \\
\hline \multirow{3}{*}{ LSWL } & R-\#3 & $3435(1.00)$ & $619(1.00)$ & $2906(1.00)$ & $1287(1.00)$ & $1282(1.00)$ \\
& R-\#4 & $6870(2.00)$ & $1332(2.15)$ & $6435(2.21)$ & $2631(2.04)$ & $2618(2.04)$ \\
& R-\#5 & $9500(2.77)$ & $2391(3.86)$ & $9412(3.24)$ & $4640(3.61)$ & $4537(3.54)$ \\
\hline
\end{tabular}

$($ ratio $)=($ wave force of $\mathrm{R}-\# \mathrm{~N}) /($ wave force of $\mathrm{R}-\# 3), \mathrm{N}=3,4,5$.

However, according to the change of wave height at LSWL, most of the models undergo a nonlinear increase of the wave force with a higher wave height increasing from wave R-\#3 (3.435 m) to wave R-\#5 $(9.5 \mathrm{~m})$. When the wave height at LSWL doubles (2.00 times) from wave R-\#3 (3.435 m) to wave R-\#4 $(6.87 \mathrm{~m})$, the wave forces increase by about 2.04-2.21 times, which is consistent with the linear wave theory with wave height. However, when the wave height increases by 2.77 times from wave R-\#3 (3.435 m) to wave R-\#5 (9.5 m), the wave forces increase by about 3.24-3.86 times. It is considered that the increased rate of the wave force (about 3.24-3.86 times) is higher than the increased rate of the wave height (about 2.77 times) because the wave height increases nonlinearly due to the occurrence of shoaling at the higher wave height (R-\#5) in shallow water (LSWL), and the wave force also increases with increasing wave height [26].

Judging from the test results with respect to the support structure type, the increasing effect of the wave force is about 3.86 times for the monopile, and 3.54-3.61 times for the hybrid, and 3.24 times for the GBS, respectively. That is, the larger the diameter of the support structure, the less the effect of the nonlinear increase of the wave force. This is because the increase in wave force due to shoaling decreases as the diameter of the support structure increases. In other words, the larger the diameter of the support structure within the range of this study, the larger the diffraction effect is, and the increase in wave force due to shoaling is suppressed. According to the study of Aashamar [19], it was found to get lower wave slamming forces on truss structure members than on a monopile. In addition, according to other theoretical studies [3], it has been reported that the impact wave force was somewhat reduced when the diameter of the support structure increased within a certain range, as presented in Figure 12. In GBS and hybrid, the wave force at LSWL is somewhat higher than that at HSWL and MSL over wave height $6.87 \mathrm{~m}$. As described in Section 3.2, it is considered that, as the water depth is lowered, the larger projected area of these two types affects the increase of the wave force, and the increase of the wave force at the higher wave height is larger. 


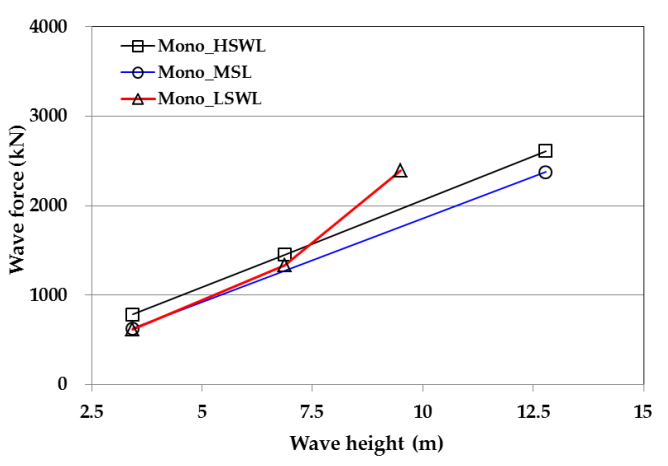

(a)

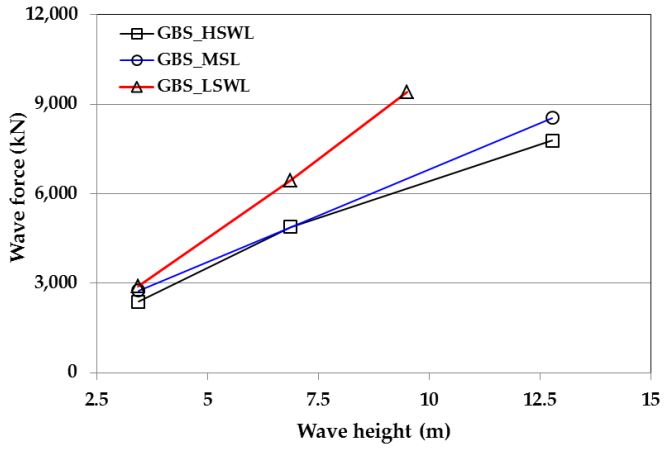

(b)

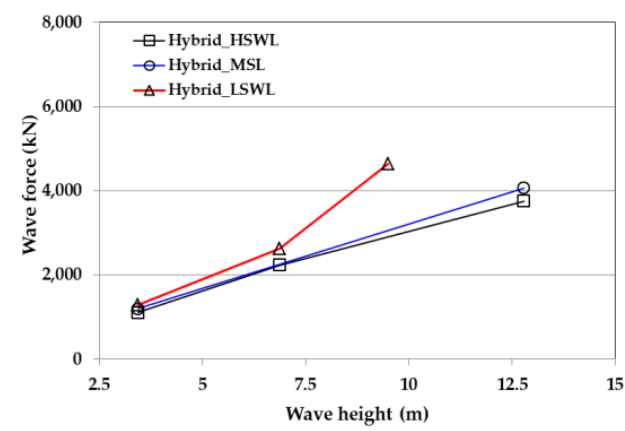

(c)

Figure 11. Wave force patterns to $H_{w}$ under regular waves: (a) monopile; (b) GBS; (c) hybrid.

Figure 13 plots the wave heights measured under application of wave R-\#3 and wave R-\#5 with the support structures. The wave heights were measured at three spots: two spots (H1, H2) located $26 \mathrm{~m}$ in front of the models and one spot (H3) located $2 \mathrm{~m}$ behind of the models with respect to the wave direction, as presented in Figure 4 . Wave nonlinearity or shoaling can be clearly identified in wave R-\#5 at LSWL [4,5,14]. Namely, the wave crest is seen to increase sharply and the wave trough to flatten. This wave nonlinearity at shallow water depth is thus likely to influence the wave force acting on the support structures for wave R-\#5 at LSWL.

As indicated in Table 5, the wave conditions at LSWL of this study correspond to those of a transitional zone. When the waves enter the transitional zone, shoaling starts and makes the waves become higher and steeper to finally undergo breaking. Figure 14 provides the relationship between the wave conditions of this study and the wave breaking criteria (diagonal line) at the transitional zone. It appears that wave R-\#5 of this study (circle area), which corresponds to the high wave height case, is close to the wave breaking criteria. This makes it possible to confirm the occurrence of wave shoaling for wave R-\#5 and its influence on the wave force, especially in shallow water at LSWL, as presented in Figure 14.
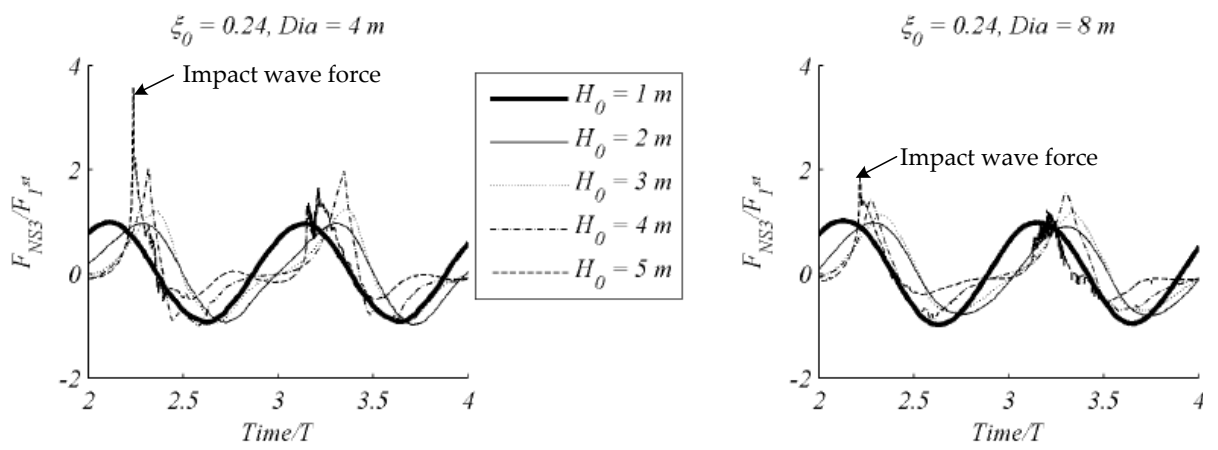

Figure 12. Extreme wave force to wave height and diameter of structure [3]. 


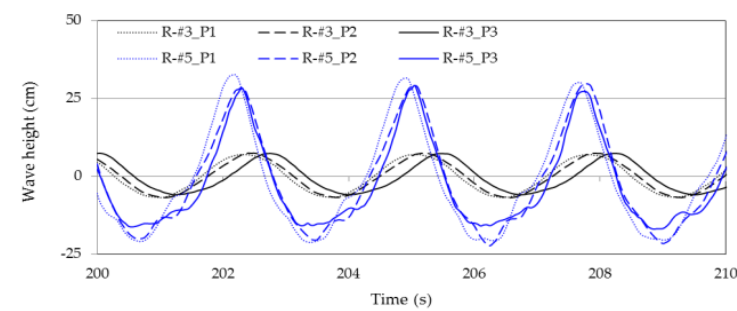

(a)

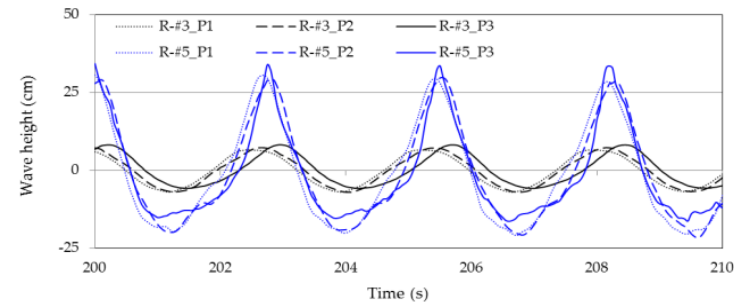

(c)

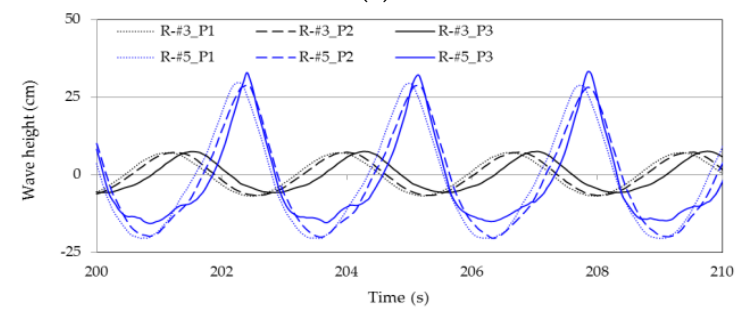

(e)

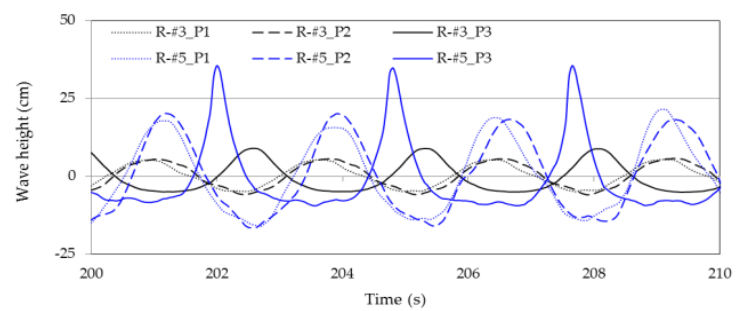

(b)

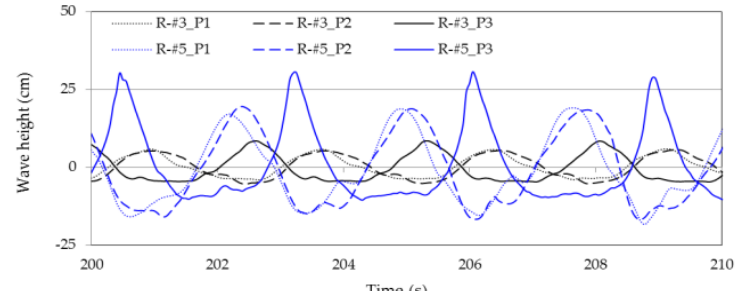

(d)

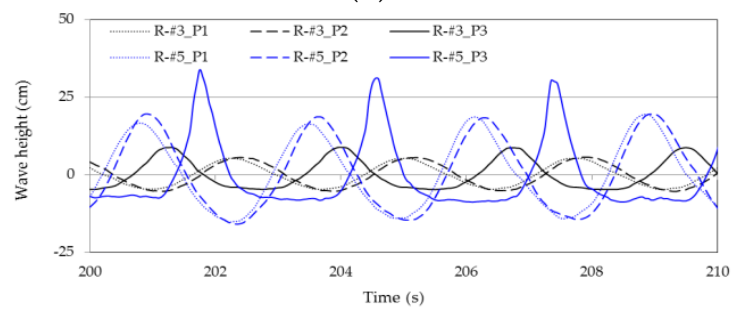

(f)

Figure 13. Measured wave heights under regular waves: (a) monopile-HSWL; (b) monopile-LSWL; (c) GBS-HSWL; (d) GBS-LSWL; (e) hybrid-HSWL; (f) hybrid-LSWL.

Figure 15 arranges the measured wave pressure distribution along with test model height according to the wave height (R-\#3 and R-\#5) for each of the considered test models. The wave pressure was measured at $50 \mathrm{~Hz}$ and Figure 15 indicates the pattern along the water depth direction at the moment when the wave pressure shows the maximum value. The monopile exhibits a typical parabolic pattern of the wave pressure. On the other hand, the wave pressure of GBS shows maximum values at mid-height of the test model, whereas the wave pressure of hybrid undergoes sharp changes at the connection between the bottom base and the multi-piles.

Judging by the overall trends, the measured wave pressures increase almost linearly as the wave heights increase. Shoaling affects the wave force due to the nonlinear variation of the wave height, so it is difficult to identify shoaling effects by the wave pressure distribution along to the water depth direction. However, it is believed that the wave pressure drop near the sea surface in GBS has also contributed to the diffraction effect. In addition, the increase in pressure at the mid-height of GBS is considered to be due to the fact that the bottom part of the GBS is composed of a cone shape and the wave pressure is added along the slope of the cone.

Table 5. Wave breaking criteria according to water depth $[4,14,22]$.

\begin{tabular}{cccc}
\hline \multirow{2}{*}{ Water Depth } & \multicolumn{2}{c}{$\Rightarrow$ Waves Higher and Steeper } \\
\cline { 2 - 4 } & & Shoaling & Breaking \\
\hline Deep water & $h>\frac{L_{W}}{2}$ & - & $\frac{H_{W}}{L_{W}}>0.142 \fallingdotseq 1 / 7$ \\
Transitional zone & $\frac{L_{W}}{2}<h<\frac{L_{W}}{20}$ & - & $\frac{H_{W}}{L_{W}}>0.142 \tanh \left(\frac{2 \pi h}{L_{W}}\right)$ \\
Shallow water & $h<\frac{L_{W}}{20}$ & - & $\frac{H_{W}}{h}>0.78$ \\
\hline
\end{tabular}




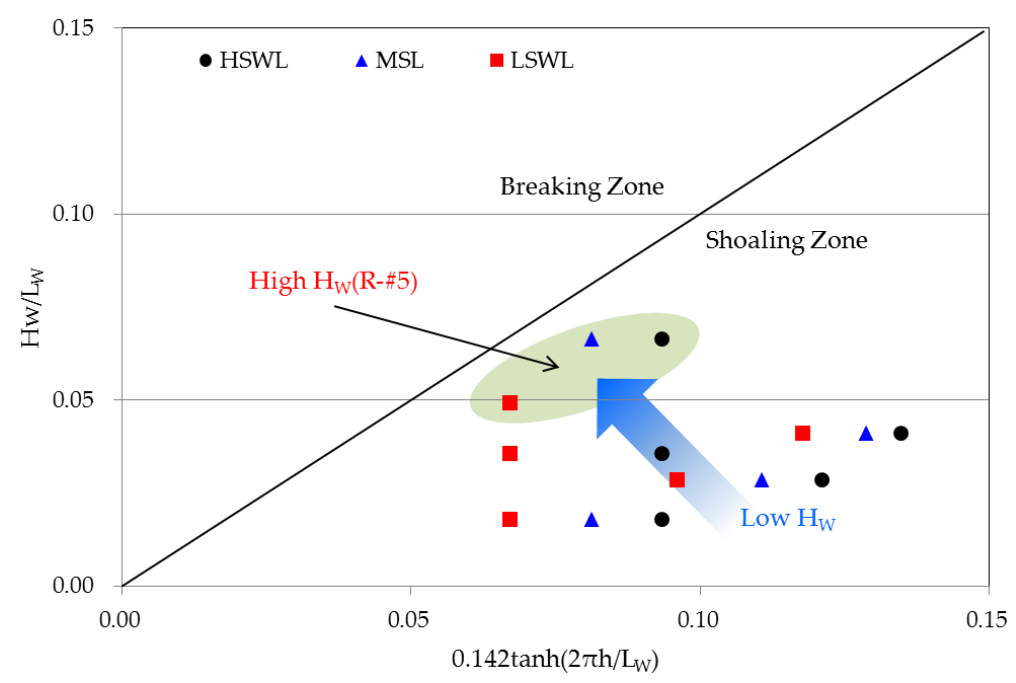

Figure 14. Relationship between wave conditions of this study and wave breaking criteria.

\subsection{Wave Forces According to Wave Periods of Irregular Waves}

Figures 16-18 plot the results of the wave force tests measured for each of the considered test models under irregular wave conditions. Table 6 summarizes the maximum amplitudes of the wave forces to irregular wave conditions for the real-scale models, and Figure 19 plots the maximum amplitude of the wave forces for the real-scale models subjected to irregular waves. The measured wave force to wave period under irregular wave exhibits a tendency different from wave force under regular wave which presents a tendency that the wave force gradually decreases the overall wave period. In view of Table 6 and Figure 19, most of the support structures undergo gradual decrease of the wave force when the wave period increases from wave IR-\#1 (7.5 s) to wave IR-\#2 (9.5 s) at the three sea levels, which indicate similar tendency with regular wave condition. However, a slight increase of the wave force occurs when the wave period increases from wave IR-\#2 (9.5 s) to wave IR-\#3 (13.7 s).

The wave force shows large variation according to the wave period with ranges of about $0.74-1.00$ at HSWL and 0.62-0.80 at MSL. However, smaller variation is observed at LSWL with a range of 0.96-1.14. Furthermore, at the LSWL, the wave force to the long-period wave $(13.7 \mathrm{~s})$ tends to be slightly higher than that of the short period wave $(7.5 \mathrm{~s})$, contrary to the test result in the regular wave condition in which the wave force to the long-period wave (13.7 s) tends to be lower than that of the short period wave (7.5 s). This is because shoaling is likely to occur in the LSWL and the irregular wave contains a high wave height component so that the wave force change due to shoaling in an irregular wave can be more sensitive than that in the regular wave condition. In addition, the change in the wave force of the irregular wave caused by shoaling becomes more apparent in the long period than in the short period wave.

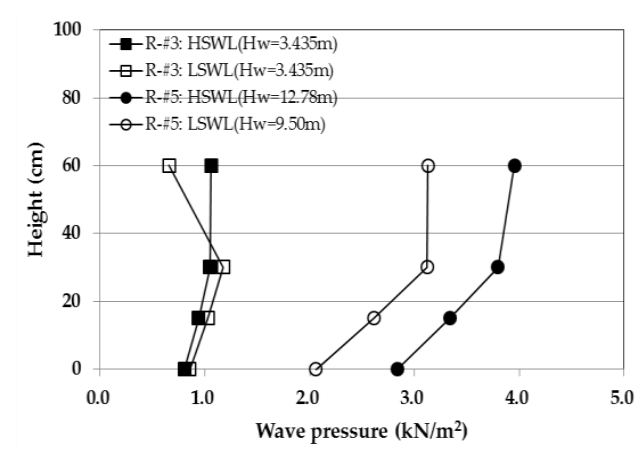

(a)

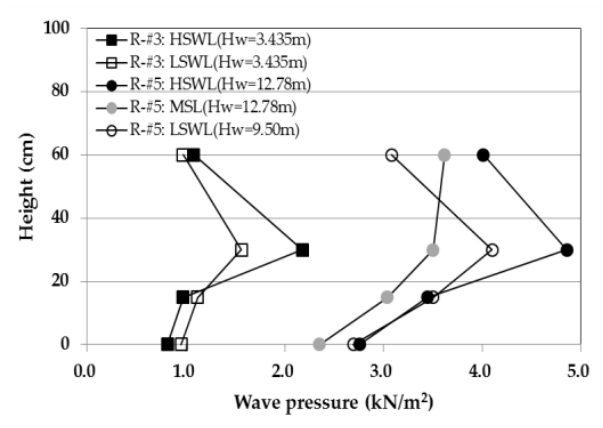

(b)

Figure 15. Cont. 


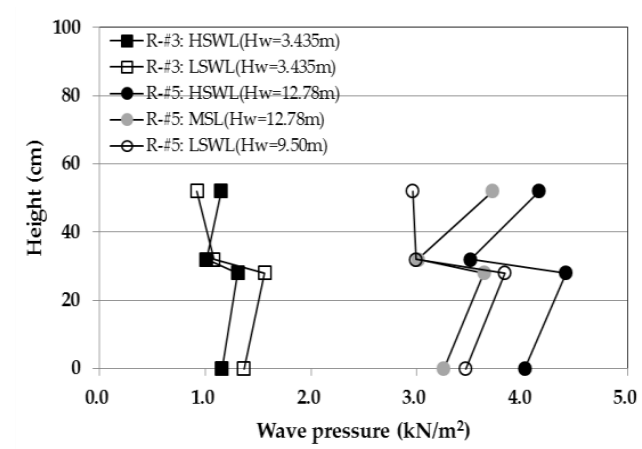

(c)

Figure 15. Measured wave pressure: (a) monopile; (b) GBS; (c) hybrid.

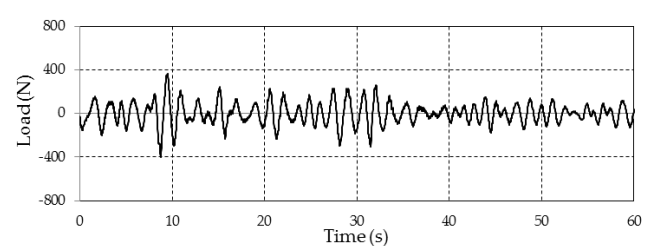

(a)

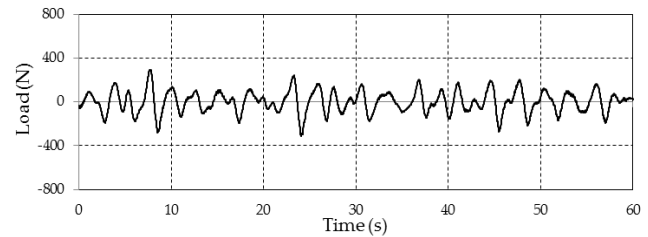

(c)

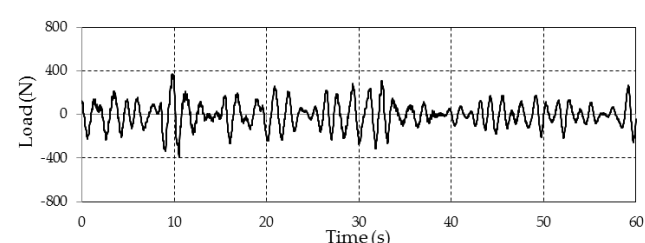

(b)

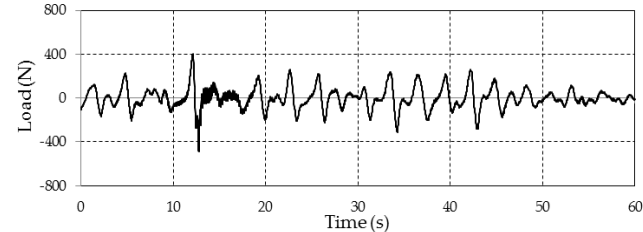

(d)

Figure 16. Measured wave forces for monopile under irregular waves: (a) IR-\#1: HSWL; (b) IR-\#1: LSWL; (c) IR-\#3: HSWL; (d) IR-\#3: LSWL.

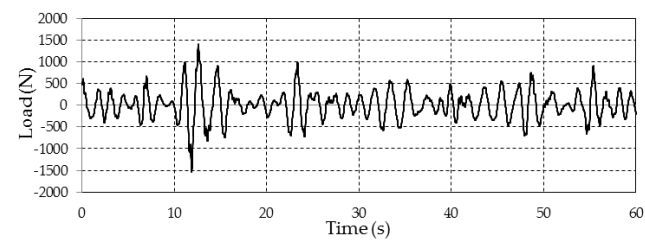

(a)

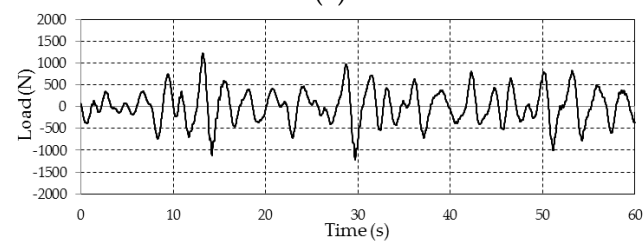

(c)

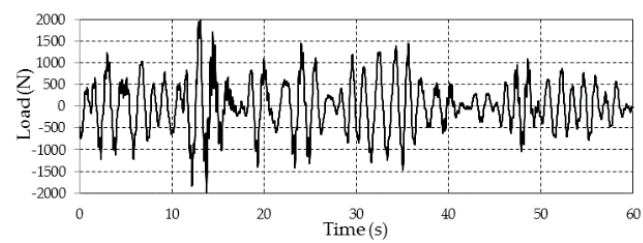

(b)

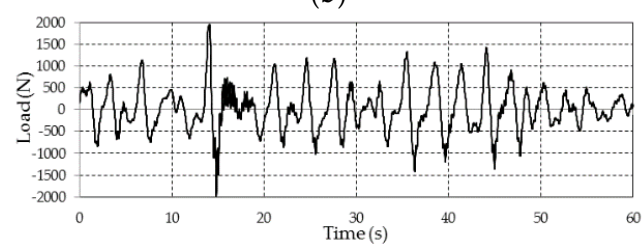

(d)

Figure 17. Measured wave forces for GBS under irregular waves: (a) IR-\#1: HSWL; (b) IR-\#1: LSWL; (c) IR-\#3: HSWL; (d) IR-\#3: LSWL.

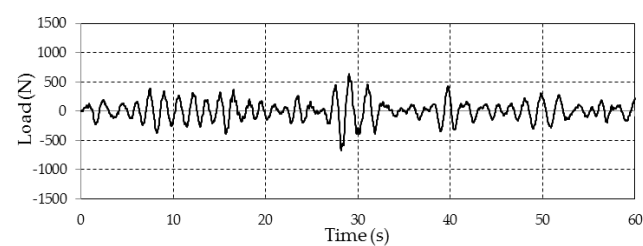

(a)

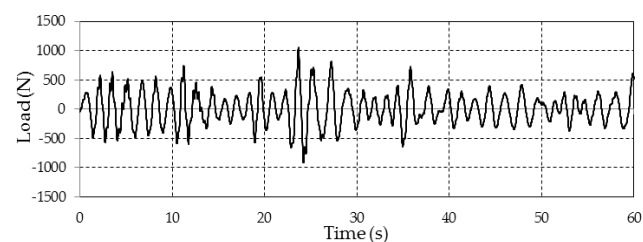

(b)

Figure 18. Cont. 


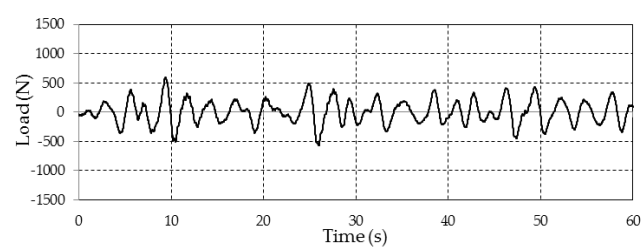

(c)

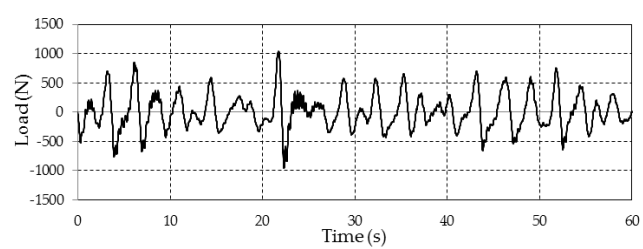

(d)

Figure 18. Measured wave forces for hybrid under irregular waves: (a) IR-\#1: HSWL; (b) IR-\#1: LSWL; (c) IR-\#3: HSWL; (d) IR-\#3: LSWL.

Table 6. Summary of maximum wave forces for real-scale models: $\mathrm{P}_{\mathrm{w}}$ under irregular waves.

\begin{tabular}{ccccccc}
\hline \multirow{2}{*}{ Sea Levels } & Wave & $\mathbf{P}_{\mathbf{w}}$ & Monopile & GBS & Hybrid 0 $^{\circ}$ & Hybrid 45 $^{\circ}$ \\
\cline { 2 - 6 } & & Sec & kN (Ratio) & kN (Ratio) & kN (Ratio) & kN (Ratio) \\
\hline \multirow{3}{*}{ HSWL } & IR-\#1 & 7.5 & $1792(1.00)$ & $5883(1.00)$ & $2186(1.00)$ & $1912(1.00)$ \\
& IR-\#2 & 9.5 & $1437(0.80)$ & $4570(0.78)$ & $1726(0.79)$ & $1694(0.89)$ \\
& IR-\#3 & 13.7 & $1332(0.74)$ & $4664(0.79)$ & $1916(0.88)$ & $1918(1.00)$ \\
\hline \multirow{3}{*}{ MSL } & IR-\#1 & 7.5 & $1544(1.00)$ & $6014(1.00)$ & $2101(1.00)$ & $2027(1.00)$ \\
& IR-\#2 & 9.5 & $1444(0.94)$ & $4251(0.71)$ & $2031(0.97)$ & $2132(1.05)$ \\
& IR-\#3 & 11.5 & $953(0.62)$ & $4095(0.68)$ & $1631(0.78)$ & $1628(0.80)$ \\
\hline \multirow{3}{*}{ LSWL } & IR-\#1 & 7.5 & $1459(1.00)$ & $7248(1.00)$ & $3185(1.00)$ & $3127(1.00)$ \\
& IR-\#2 & 9.5 & $1351(0.93)$ & $6533(0.90)$ & $2764(0.87)$ & $2781(0.89)$ \\
& IR-\#3 & 13.7 & $1662(1.14)$ & $6965(0.96)$ & $3214(1.01)$ & $3248(1.04)$ \\
\hline
\end{tabular}

$($ ratio $)=($ wave force of IR-\#N)/(wave force of IR-\#1), $\mathrm{N}=1,2,3$.

Judging from the test results with respect to the support structure type, the monopile shows a wider variation of the wave force than the GBS and Hybrid. The decreasing ratios of the wave force when the sea level lowers from HSWL to MSL and LSWL are about 0.74, 0.62 and 1.14 for the monopile, $0.79,0.68$ and 0.96 for the GBS, and $0.88,0.78$ and 1.01 for the hybrid, respectively. This is the similar tendency with the test result in the regular wave, where the larger the diameter of the support structure, the larger the diffraction effect and the effect of increasing the wave force by shoaling is reduced.

In GBS and hybrid, the wave forces at LSWL are somewhat higher than that the HSWL and MSL overall wave periods. As described in Sections 3.2 and 3.3, it is considered that, as the water depth is lowered, the larger projected area of these two types affects the increase of the wave force, and the high wave height component included in the irregular wave has an influence on the increase of the wave force.

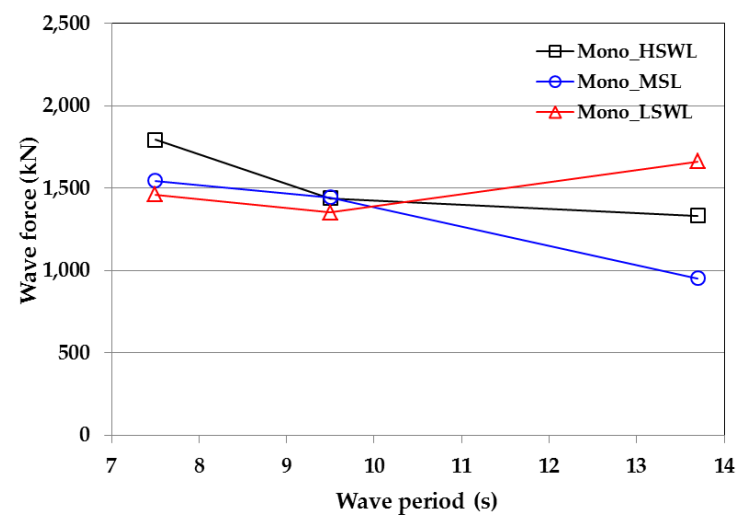

(a)

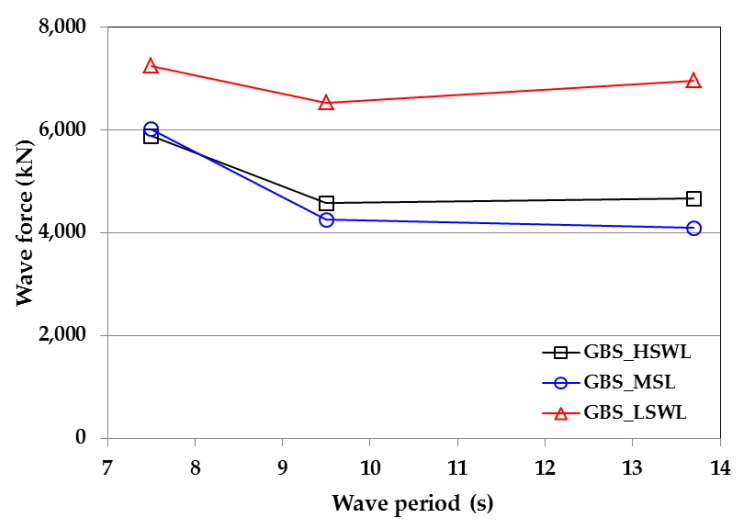

(b)

Figure 19. Cont. 


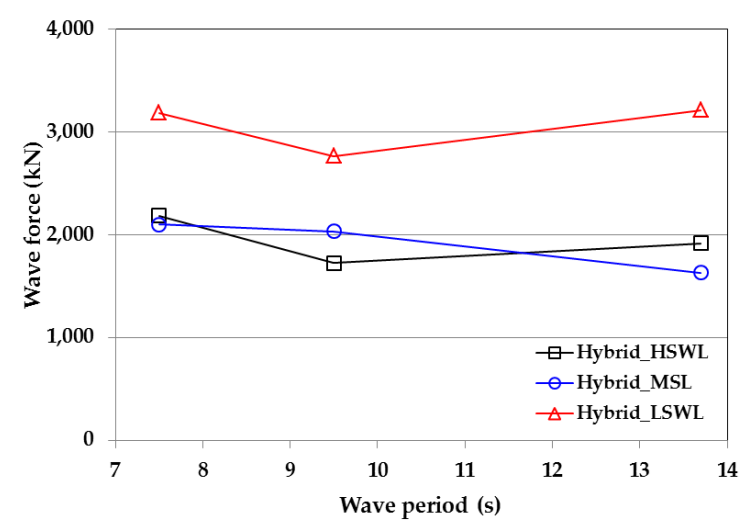

(c)

Figure 19. Wave force patterns under irregular waves: (a) monopile; (b) GBS; (c) hybrid.

\subsection{Comparison Test Results with Analytical Results}

In order to verify the wave force pattern from the test for sea levels and wave heights under regular wave conditions, a numerical analysis was performed on three test models using an in-house hydrodynamic analysis tool $[25,27]$ developed to reflect the diffraction effects of a large-sized circular member. A comparison of test and analytical results for wave forces is presented in Figure 20 [25].

As a result of the comparison of the wave force, the ratios of the test wave force to the analytical wave force in the HSWL and MSL range from 1.03 to 1.21 for the monopile, 0.82 to 0.98 for the GBS, and 0.65 to 0.74 for the hybrid, respectively. The variation of the ratios between the test and analytical results due to wave height changes is not large in all three types in the HSWL and MSL. This means that both the test and analytical results are consistent. The overall tendency in HSWL and MSL indicates that the ratios of the test wave force to the analytical wave fore tend to decrease slightly as the wave height increases in the three test models. This means that as the wave height increases, the test results are slightly smaller than the analytical results in the HSWL and MSL.

On the other hand, the test wave forces indicate a considerable difference from the analytical wave forces in LSWL. The ratios of the test wave force to the analytical wave force in the LSWL range from 1.14 to 1.60 for the monopile, 0.98 to 1.15 for the GBS, and 0.67 to 0.87 for the hybrid, respectively. The ratios of the test wave force to the analytical wave force increase significantly with the increase of wave height in LSWL, as presented in Figure 20. This means that as the wave height increases, the test results become much larger than the analytical results. It seems to be due to the wave nonlinearity such as shoaling or breaking, which cannot be considered in the analysis tools of this study, occurring in the shallow water. In addition, GBS results in a slower rate of increase in wave force at higher wave heights, which is similar to the trend in the test. It seems to be due to the fact that the diffraction effect generated in the large-sized circular member compensates the nonlinear effect of the wave force due to the shoaling, as in the test results presented in Figure 11.

The analytical wave forces for the hybrid model has resulted in an over-estimation compared to the test results, which seems to be caused by the complicated shape of the hybrid model that combines a large diameter member at the bottom with slender members at the upper part. In order to obtain accurate wave force in shallow water analytically, it needs a more sophisticated hydrodynamic model to account for wave nonlinearity in the shallow water as well as complicated structural shapes. 


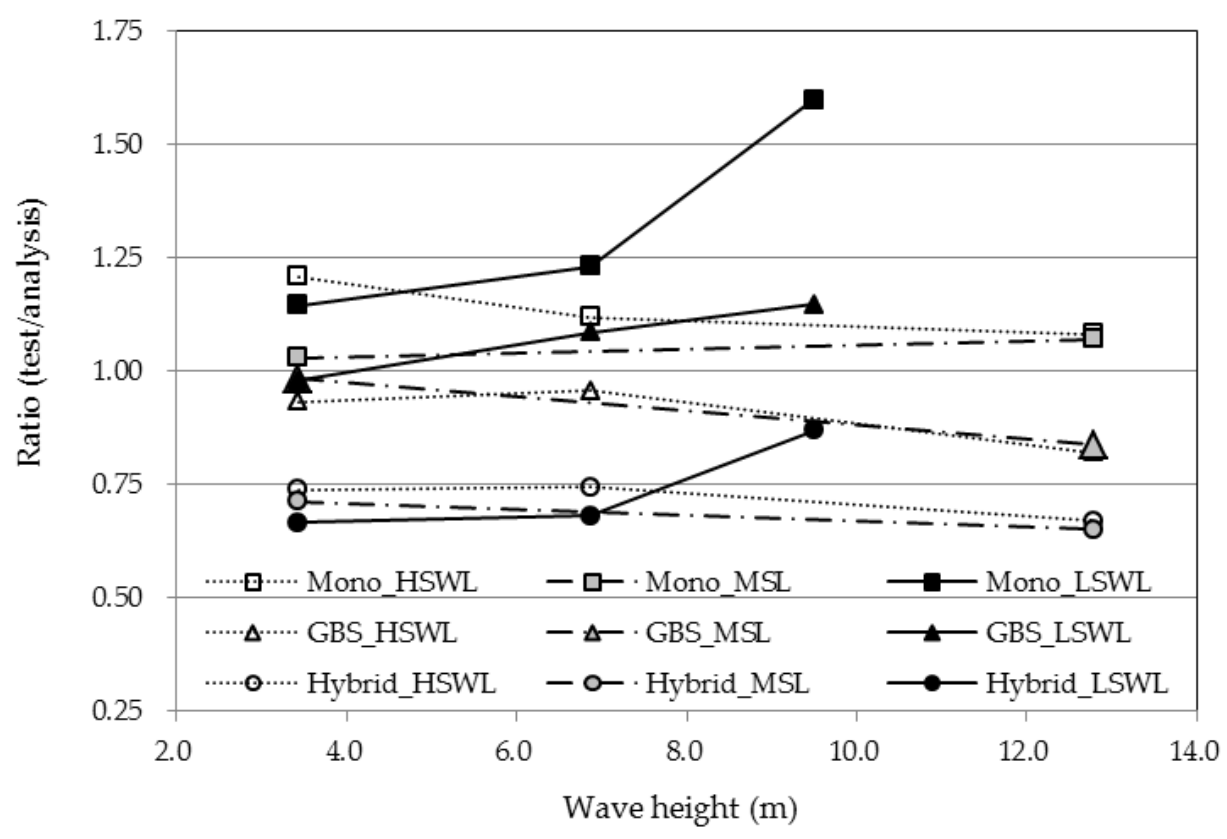

Figure 20. Wave force ratios to wave height under regular waves: test/analysis.

\section{Conclusions}

This study investigated the effects of sea levels and wave conditions on the wave force. To that goal, wave force tests were carried out considering three sea levels and eight wave conditions for the three types of offshore support structure. The analysis of the resulting wave force patterns with respect to the sea levels and wave conditions led to the following observations.

The occurrence of shoaling in shallow water induces a significant increase of the wave height and the wave force also increases with increasing wave height. According to the change of wave height in shallow water, most of the test models of this study undergo nonlinear increase of the wave force with higher wave height increasing. In addition, the larger the diameter of the support structure within the range of this study, the larger the diffraction effect is, and the increase in wave force due to shoaling is suppressed. Accordingly, it is found that the large-sized member within the range of this study undergoes a smaller variation of the wave force due to the wave nonlinearity according to the wave conditions and sea levels than the slender members.

Nonlinear wave force due to shoaling occurs not only in wave height but also in wave period. Under irregular wave at the shallow water, the wave force to the long-period wave tends to be slightly higher than that of the short period wave, contrary to the test result in the regular wave condition in which the wave force to the long-period wave tends to be lower than that of the short period wave. It is considered that the high wave height component included in the irregular wave has an influence on the shoaling, resulting in an increase of the wave force. Also, it is found that the change in the wave force of the irregular wave caused by shoaling becomes more apparent in the long period than in the short period wave.

Author Contributions: Y.-J.J. is the PI of the research project and the person who planned most of the test program and was the main writer of the paper; M.-S.P. is the person who performed most of the test works; J.K. is the person who assisted the test works and data analyzing; S.-H.S. is the person who assisted with the data analysis.

Funding: This study was supported by the Ministry of Trade, Industry, and Energy of South Korea, Project No: 20183010025540 (development on installation system of XL monopole for offshore wind turbines in Korea) and Project No: 20123010020110 (development of a hybrid substructure system for an offshore wind farm).

Conflicts of Interest: The authors declare no conflict of interest. 


\section{References}

1. Park, M.S.; Koo, W.C.; Choi, Y.R. Hydrodynamic interaction with an array of porous circular cylinders. Int. J. Naval Arch. Ocean Eng. 2010, 2, 146-154. [CrossRef]

2. Park, M.S.; Koo, W.C.; Kawana, K. Numerical analysis of the dynamic response of an offshore platform with a pile-soil foundation system subjected to random waves and currents. J. Waterway Port Coast. Ocean Eng. ASCE 2012, 138, 275-285. [CrossRef]

3. Christensen, E.D.; Bredmose, H.; Hansen, E.A. Extreme wave forces and wave run-up on offshore wind turbine foundations. In Proceedings of the Copenhagen Offshore Wind Conference, Copenhagen, Denmark, 10-12 March 2005; pp. 1-10.

4. Michael, R.G. Wave Shoaling and Refraction; Springer: Berlin, Germany, 2011.

5. Orzech, M.; Herbers, T.H.C.; Elgar, S.; Guza, R.T. Shoaling transformation of wave frequency-directional spectra. J. Geophys. Res. 2003, 108, 1-17.

6. De Vos, L.; Frigaard, P.; Rouck, J.D. Wave run-up on cylindrical and cone shaped foundations for offshore wind turbines. Coast. Eng. 2007, 54, 17-29. [CrossRef]

7. Chella, M.A.; Torum, A.; Myrhaug, D. An overview of wave impact forces on offshore wind turbine substructures. Energy Proc. 2012, 20, 217-226. [CrossRef]

8. Cao, D.; Yat-Man, E.L.; Jian, W.; Huang, Z. An experimental study of wave runup: cylinder fixed in waves versus cylinder surging in still water. In Proceedings of the 3rd International Conference on Coastal and Ocean Engineering, Tokyo, Japan, 15 February 2016.

9. Fischer, T.; De Vries, W.; Schmidt, B. Upwind Design Basis (WP4: Offshore Foundations and Support Structures). In Upwind; University Stuttgart: Stuttgart, Germany, 2010.

10. Brook-Hart, W.; Jakson, P.A.; Meyts, M.; Gifford, P. Competitive Concrete Foundations for Offshore Wind Turbines; International Foundation: Fairfield, NJ, USA, 2010.

11. Park, M.S.; Jeong, Y.J.; You, Y.J.; Lee, D.H. Numerical analysis of a gravity substructure with suction bucket foundation for 5MW offshore wind turbine. Int. J. Emerg. Technol. Adv. Eng. 2015, 5, 59-65.

12. Park, M.S.; Jeong, Y.J.; You, Y.J. Safety evaluation of a hybrid substructure for offshore wind turbine. Adv. Mater. Sci. Eng. 2016, 1-20. [CrossRef]

13. NEDO. NEDO Offshore Wind Energy Progress; NEDO: Tokyo, Japan, 2013.

14. Tsai, C.P.; Chen, H.B.; Huang, M.J. Wave shoaling on steep slopes and breaking criteria. In Proceedings of the 12th International Offshore and Polar Engeneering Conference, Kitakyushu, Japan, 26-31 May 2002. ISOPE-I-02-353.

15. Schloer, S.; Bredmose, H.; Bingham, H.B. Irregular wave forces on monopile foundation: Effect of full nonlinearity and bed Slope. In Proceedings of the 30th International Conference on Ocean, Offshore and Arctic Engineering, Rotterdam, The Netherlands, 19-24 June 2011. OMAE2011-49709.

16. Jeong, Y.J.; Park, M.S.; You, Y.J. Experimental study on wave forces to offshore support structures. Struct. Eng. Mech. 2016, 60, 193-209. [CrossRef]

17. Marino, E.; Borri, C.; Peil, U. A fully nonlinear wave model to account for breaking wave impact loads on offshore wind turbines. J. Wind Eng. Ind. Aerodyn. 2011, 99, 483-490. [CrossRef]

18. Aashamar, M.Z. Wave Slamming Forces on Truss Support Structures for Wind Turbines. Master's Thesis, Norwegian University of Science and Technology, Trondheim, Norway, 2012.

19. Ros, X. Impact Forces on a Vertical Pile from Plunging Breaking Waves. Master's Thesis, Norwegian University of Science and Technology, Trondheim, Norway, 2011.

20. Kudeih, M.; Cornett, A.; Nistor, I. An experimental study of wave and current-induced forces on a compact linear array of vertical cylinders in shallow water. Coast. Eng. 2010, 32, 1-10. [CrossRef]

21. Henry, P.Y.; Myrhaug, D. Wave-induced drag force on vegetation under shoaling random waves. Coast. Eng. 2013, 78, 13-20. [CrossRef]

22. DNV. Offshore Standard DNV-OS-J101: Design of Offshore Wind Turbine Structures; Det Norske Veritas AS: Høvik, Norway, 2013.

23. Goda, Y. Random Seas and Design of Maritime Structures, 3rd ed.; World Scientific: Singapore, 2010.

24. Jeong, Y.J.; Park, M.S. Experimental study on wave force variation to sea levels of large circular marine structures. In Proceedings of the 12th International Conference on Structural Safety \& Reliability, Vienna, Austria, 6-10 August 2017; pp. 907-915. 
25. Jeong, Y.J.; Park, M.S.; Kim, J. Comparing wave force and wave-induced overturning moment of three offshore support structures. In Proceedings of the ASME 2017 36th International Conference on Ocean, Offshore and Arctic Engineering, Trondheim, Norway, 25-30 June 2017. OMAE2017-61073.

26. Peng, Z. Wave slamming impact on offshore wind turbine foundations. Coast. Eng. Conf. 2014, 34, 1-8. [CrossRef]

27. Park, M.S.; Jeong, Y.J.; You, Y.J.; Lee, D.H.; Kim, B.C. Numerical Analysis of a Hybrid Substructure for Offshore Wind Turbines. Ocean Syst. Eng. 2014, 4, 169-183. [CrossRef]

(C) 2019 by the authors. Licensee MDPI, Basel, Switzerland. This article is an open access article distributed under the terms and conditions of the Creative Commons Attribution (CC BY) license (http://creativecommons.org/licenses/by/4.0/). 